\title{
Impact of the physical environment of psychiatric wards on the use of seclusion
}

\author{
P. S. van der Schaaf, E. Dusseldorp, F. M. Keuning, W. A. Janssen and E. O. Noorthoorn
}

\section{Background}

The physical environment is presumed to have an effect on aggression and also on the use of seclusion on psychiatric wards. Multicentre studies that include a broad variety of design features found on psychiatric wards and that contro for patient, staff and general ward characteristics are scarce.

\begin{abstract}
Aims
To explore the effect of design features on the risk of being secluded, the number of seclusion incidents and the time in seclusion, for patients admitted to locked wards for intensive psychiatric care.
\end{abstract}

\section{Method}

Data on the building quality and safety of psychiatric as well as forensic wards $(n=199)$ were combined with data on the frequency and type of coercive measures per admission ( $n=23868$ admissions of $n=14834$ patients) on these wards, over a 12-month period. We used non-linear principal components analysis (CATPCA) to reduce the observed design features into a smaller number of uncorrelated principal components. Two-level multilevel (logistic) regression analyses were used to explore the relationship with seclusion. Admission was the first level in the analyses and ward was the second level.

\section{Results}

Overall, 14 design features had a significant effect on the risk of being secluded during admission. The 'presence of an outdoor space', 'special safety measures' and a large 'number of patients in the building' increased the risk of being secluded. Design features such as more 'total private space per patient', a higher 'level of comfort' and greater 'visibility on the ward', decreased the risk of being secluded.

\section{Conclusions}

A number of design features had an effect on the use of seclusion and restraint. The study highlighted the need for a greater focus on the impact of the physical environment on patients, as, along with other interventions, this can reduce the need for seclusion and restraint.

\section{Declaration of interest}

None.
Patient aggression and severely disturbed behaviour on psychiatric wards threatens the safety of both patients and staff. Actual violence and aggression have been identified as the most frequent reason for the use of coercive measures. ${ }^{1,2}$ These measures have several side-effects ${ }^{3,4}$ and are therefore controversial. In The Netherlands, debate is focused on the need to drastically reduce the use of seclusion. Recently, the Dutch Health Care Inspectorate stated that solitary seclusion of patients should be phased out: 'a sick patient must never be left alone.' In-patient aggression and conflict results from a complex interaction of the individual characteristics of patients, staff characteristics and contextual characteristics, such as the physical environment of the ward. ${ }^{6}$ Little is known about the impact of the physical environment in psychiatric hospitals in general and, more specifically, to what degree it might contribute to in-patient aggression and the use of coercive measures. ${ }^{7}$ To date, most studies are primarily focused on the impact of patient and staff characteristics. ${ }^{8-10}$ Many studies are small, covering a single ward or hospital. In these small studies the physical environment is stable. Also, the impact of the physical environment on psychiatric patients' behaviour has not been systematically investigated. Some case studies consist of descriptive evaluations of moves from old to new buildings, and report for instance a reduction of psychiatric symptoms, improvement in ward atmosphere or reduced violence and vandalism. ${ }^{11,12}$ It is only recently that architects and psychiatrists have started to pay attention to the rationale and effects of physical design, encouraged by research in the field of environmental psychology and evidencebased design in other healthcare settings, such as general hospitals or nursing homes. These studies have demonstrated the impact of the physical environment on emotional states, behaviour and even patient outcomes. ${ }^{13-15}$ The purpose of this study is to systematically explore the relationship between the various environmental design features of (locked) psychiatric wards and the incidence and prevalence of seclusion.

In the literature, seclusion is commonly defined as bringing a patient into a locked room where he or she is alone and able to move around. ${ }^{16}$ Some authors paid attention to safety preconditions, design and atmosphere of seclusion rooms. They described a seclusion room as a specially designated area, minimally furnished, bare in such a way that the patient is unable to either accidentally or consciously damage or hurt themselves or others. ${ }^{1,16}$ These definitions make no distinction about the type of rooms or designated areas in which patients are locked up. This is of note because from the patient's point of view it makes quite a difference whether they are taken to an empty room, with the highest safety level, or to a designated area with personal attention and comforting surroundings. ${ }^{17,18}$ In Dutch mental healthcare several types of rooms are used for seclusion. There are rooms or designated areas with different designs, furnishings, atmosphere and safety levels, such as seclusion rooms, isolation rooms, 'time out' rooms or (stripped and lockable) bedrooms. In this study we focused on seclusion rooms. In these rooms the highest safety level is applied to the design and interior with a violence-proof finish and minimal use of furniture.

Large differences exist between wards in the use of coercive measures with respect to seclusion incidence and duration. In a large Dutch study of 12 mental health trusts the incidence of seclusion ranged from 116 to 948 incidents per 1000 admissions. ${ }^{19}$ In a different study of 29 admission wards in seven mental health trusts the duration of seclusion varied between 1 to 157 hours per 1000 bed hours. ${ }^{20}$ In the current study we assumed that part of the heterogeneity between wards could be explained by design features of the ward. Our research questions were: can design features (the physical environment) of the ward contribute to the risk of being 
secluded, while controlling for a range of potential confounding patient, staff and general ward characteristics? And if so, what are the implications of the findings for the design of psychiatric hospitals?

\section{Method}

\section{Setting and data collection}

To assess the relationship between the design features of the ward and coercive measures such as seclusion, we combined two major data sources in The Netherlands. First, data from a multicentre study on building quality and safety of 77 psychiatric hospitals ${ }^{21}$ and second, a benchmark study on the use of coercive measures in 16 psychiatric hospitals. The data collection period for both data sources was restricted to exactly 1 year, 2009.

The first data-set concerned the design features of 505 locked wards covering $93 \%$ of all such wards in The Netherlands. The design features were collected on a site visit by a trained researcher and randomly by a second researcher, showing percentages of agreement between 80 and 90\%, which is considered high. ${ }^{21} \mathrm{~A}$ ward was defined as a physically distinct area with a 'private' entrance (which can be locked), several (bed)rooms, corridors and common spaces (living room, kitchen, garden, smoking area, etc.), shared by a fixed group of patients and staff. In most cases two or more wards together function as an organisational entity with the same staff. The type of ward was categorised into one of two groups: admission wards and non-admission wards. Admission wards were defined as wards that admit acute patients from a catchment area with no restrictions. In the non-admission wards, patients are admitted for treatment and rehabilitation or for specialised or forensic care. The target population of the wards was categorised as: adolescent and adult patients (15-65 years), and elderly patients ( 65 years and older).

The second database contained data from 199 wards on the use of coercive measures as well as patient and staff characteristics. Data on coercive measures were collected by using the Argus scale. ${ }^{19}$ The Argus scale was completed on a day-to-day basis by nurses for those patients who experienced one or more coercive measures. The reliability of the Argus scale has proved to be fair to good (Cohen $\kappa=0.64-0.92) .{ }^{22}$ Data on patient characteristics such as date of birth, gender, ethnicity, marital status, the most recent ICD- $10^{23}$ and Global Assessment of Functioning (GAF) score $^{24}$ were collected from hospitals' patient information systems. Staff characteristics were collected by means of a survey covering items such as total number of nursing staff present on the ward during the day, evening and night (per shift) and the total number of staff available for patients on the ward, for example psychiatrists, doctors, psychologists or social workers.

Our final study sample consisted of 199 wards in 16 psychiatric hospitals in The Netherlands. It included data from $37 \%$ of all locked wards of hospitals with both rural and urban catchment areas. Our final data-set included data relating to a total of 2446 beds and 23868 admissions of 14834 patients.

\section{Measures}

\section{Design features of the ward}

The design features included in this study are those associated with the quality and the safety of the physical environment and the well-being of patients. A total of 115 variables per ward were observed, for example the type of rooms, the amount of private and public space (square meters), natural light and views, atmosphere and safety measures. These 115 variables were grouped into six theoretical concepts, i.e. 'families. ${ }^{25,26}$ Variables that were not independent and variables with small variance were excluded. The Appendix provides an overview of the six families of design features, including the components that resulted from the non-linear principal component analysis (CATPCA) (a more detailed version, which includes all the design features, can be found in online Appendix DS1).

\section{Outcome measures}

The Argus scale measures in detail, on a day-to-day basis, the use of seclusion as well as other coercive measures, such as mechanical and physical restraint, enforced feeding, enforced intramuscular medication and other enforced treatment. Because we focused on the impact of the physical environment of the ward on seclusion, patients needed to be actually exposed to the ward. In other words, what happened elsewhere with a patient, either on another ward or prior to the admission, was not considered relevant in this study. Therefore all coercive measures used on the first day of admission were excluded. The primary outcome measure was the use of seclusion per ward. Due to a very skewed distribution of the number of seclusions, we constructed three outcome measures.

(a) Whether or not an individual was secluded during an admission on a ward.

(b) For those secluded, the number of seclusion incidents during an admission on a ward.

(c) For those secluded, the proportion of time they were secluded (the total seclusion time divided by length of stay).

The first and second measure were adjusted for length of stay. The second and third measure only concerned a subsample of the data (i.e. 1455 admissions, 141 wards).

\section{Data analysis}

Descriptive statistics were computed for patient characteristics at patient level and design features at ward level. We used CATPCA to reduce, as much as possible, the observed design features into a smaller number of uncorrelated principal components. These analyses were performed using SPSS Statistics, version 17.0 on Windows 7. We used CATPCA, the non-linear equivalent of standard principal components analysis (PCA), as the most important advantages of non-linear over linear PCA are that nominal and ordinal variables can be included and that non-linear relationships can be modelled. ${ }^{27}$ A CATPCA was performed per family of design features. The CATPCA resulted in seven reliable components (Cronbach's $\alpha \geqslant 0.60$ ) and 17 remaining variables (Appendix). These components and remaining variables were used to estimate the impact of the physical environment on coercive measures.

Two-level multilevel (logistic) regression analyses were performed to explore this impact. Admission was the first level in the analyses and ward was the second level. These analyses were performed using the lme4 package (http://cran.r-project.org/web/ packages/lme4/) in the R-environment (http://r-forge.wu-wien.ac. at; Vienna, Austria) on Windows 7. Depending on the type of outcome variable (categorical or continuous), logistic or linear multilevel regression analyses were performed. The distributions of the second and third measure of seclusion were still positively skewed, therefore, in the analyses we used, respectively, the logtransformed and square root transformed variables. Correlation between the original and the transformed variables were 0.76 for the log-transformed and 0.95 for the square root transformed variable.

To reduce the number of design features in the analyses (and overcome problems of instability and overfitting), for each outcome measure, two series of multilevel analyses were 


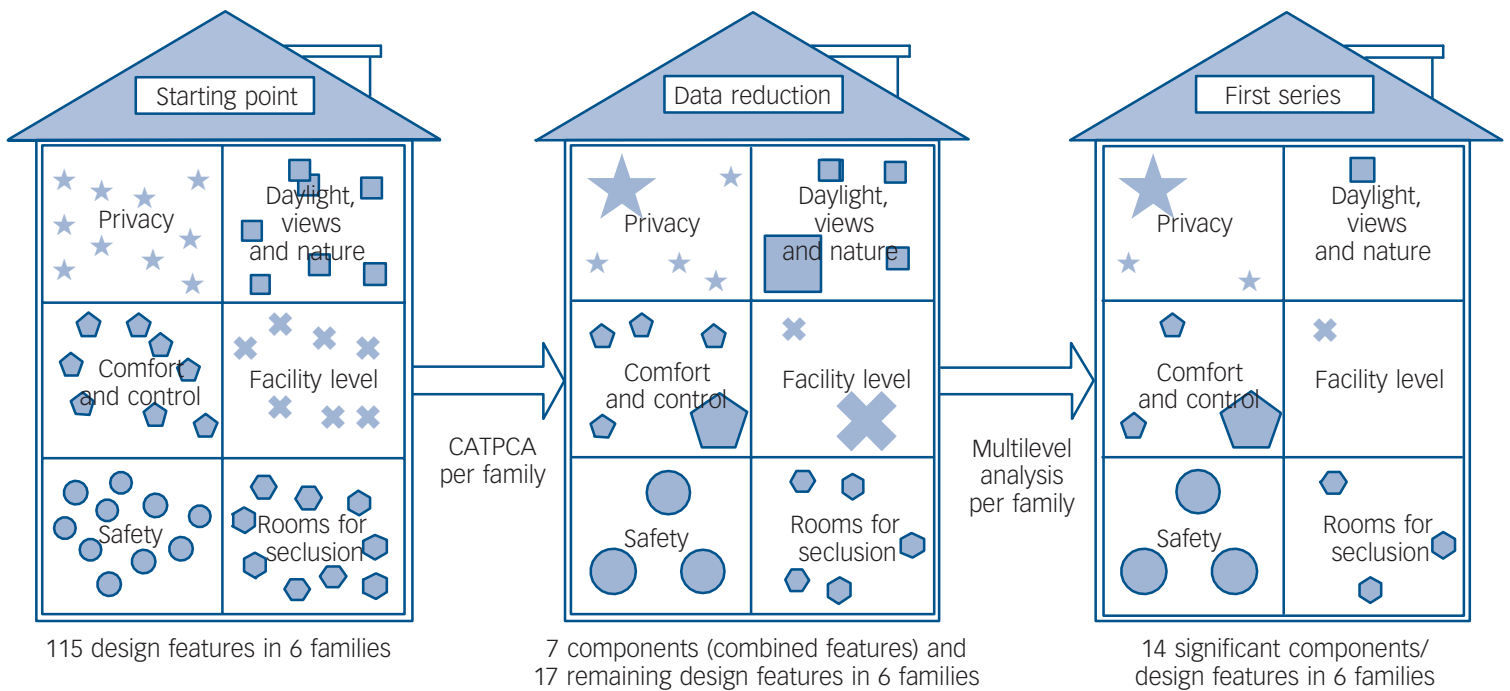

\section{Fig. 1 Data analysis steps involved in selecting design features.}

Steps involved from the starting point and data reduction stage per family of design features (non-linear principal components analysis (CATPCA)) up until the first series of multilevel analyses in order to select design features $(P<0.20)$ for the final analyses

performed. The first series were performed per family: only design features within a family were entered as predictors. From these solutions, the design features with a $P<0.20$ were selected for further analyses (Fig. 1). In a second series of multilevel analyses, two models were compared. The first model included the patient, staff and general ward characteristics as predictors. The second model included, in addition to these characteristics, all the design features that were selected in the first phase. To test whether the impact of the design features was significant, an analysis of variance (ANOVA) was performed using the goodness-of-fit statistics of these two models, and the increase in chi-squared was inspected.

\section{Results}

\section{Descriptive statistics}

Patient characteristics

The sample included 6882 women $(46.4 \%)$ and 7952 men (53.6\%), ranging in age from 10 to 100 years (mean 46.6 s.d. $=17.9)$. Most patients were diagnosed with schizophrenia, schizotypal and delusional disorders (29.8\%), mood disorders $(16.1 \%)$, personality disorders $(12.2 \%)$ and disorders due to the use of psychoactive substances (10.4\%). Table 1 shows the main patient characteristics per type of ward.

\section{Ward characteristics}

Of the wards included in the study, $46.2 \%(n=92)$ were nonadmission wards, $41.2 \%(n=82)$ were admission wards and $12.6 \%(n=25)$ were forensic wards. The number of patients per ward ranged from 4 to 32 (mean 12.3 , s.d. $=5.1$ ). The size of the wards ranged from 87.1 to $1321.5 \mathrm{~m}^{2}$ (mean 460.0 , s.d.=213.6), with an average of $13.6 \mathrm{~m}^{2}$ private space per patient (s.d.=3.6) and an average of $10 \mathrm{~m}^{2}$ per patient for common use (s.d.=3.3). Almost all wards had single rooms only $(93.6 \%$, s.d. =14.8). This high proportion is mainly the result of a strong governmental policy in The Netherlands regarding the privacy of patients. Other design features in favour of privacy and

\section{Table 1 Patient characteristics}

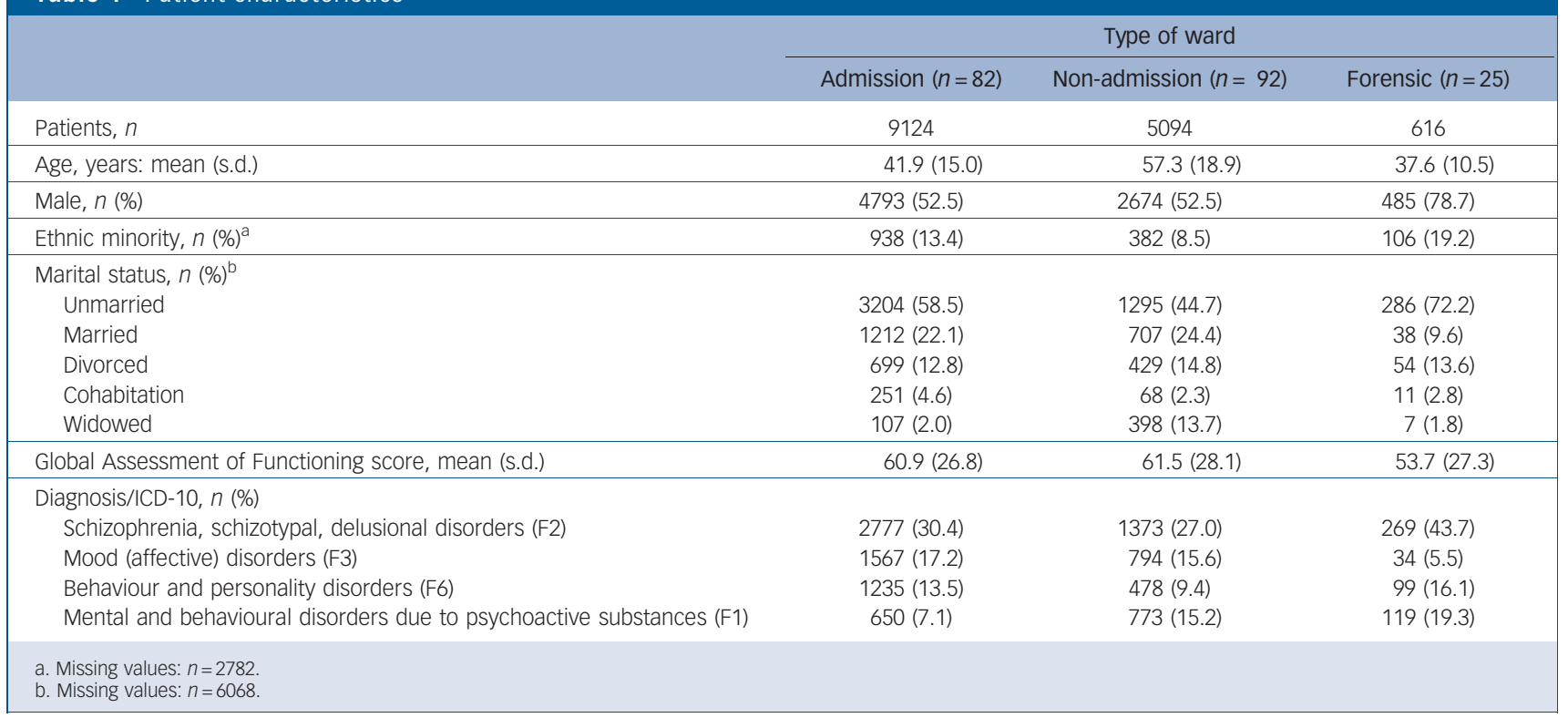


autonomy of patients also scored relatively high. Almost all wards had an outdoor space available for patients $(n=192,96.5 \%)$. The overall safety level was the highest on forensic wards, followed by admission wards and non-admission wards. Table 2 shows the main ward characteristics and design features by type of ward.

\section{Coercive measures and seclusion characteristics}

Most wards had one to six seclusion rooms available, located on or nearby the ward (mean 1.4, s.d.=1.1). Time-out rooms, isolation rooms, (stripped) bedrooms or designated areas other than seclusion rooms, where patients could be locked up, were most frequently present on forensic wards (mean 9.1, s.d.=5.0). This can be explained by the stringent safety measures that are more common on forensic wards and, partly due to that, the higher proportion of bedrooms that can be locked. In general most incidents that led to a coercive measure occurred on forensic wards. Standardised to 1000 admissions the mean number of coercive measures on forensic wards was 686.1 (s.d.=613.2), compared with an average of $545.1($ s.d. $=1470.4)$ measures on admission wards and an average of 544.4 (s.d. $=962.9$ ) measures on non-admission wards. Overall, the number of seclusion incidents per 1000 admissions varied between 0.0 and 2485.8 (mean 183.0 , s.d. $=323.6)$. In $94 \%$ of the admissions $(n=22409)$, patients were not secluded. Most of the seclusions occurred on forensic wards and the proportion of time spent in seclusion during an admission was longer on forensic wards than on other wards (Table 3).

\section{Multilevel analyses: design features and seclusion}

Table 4 gives the odds ratios (ORs) for each design feature associated with the risk of being secluded or not during an admission on a ward, when adjusted for patient, staff and general ward characteristics. Ethnic minority and marital status were not included due to the relatively large number of missing values, and univariate analyses revealed no association between these variables and the risk of being secluded. We will first describe how we arrived at this final model, and then interpret the odds ratios in Table 4.

From the first series of multilevel analyses, performed per family of design features, 14 design features were selected (Fig. 1). The importance of a family to the prediction can be read from how many features per family were selected. The family 'safety' appeared to be the most important. From this family all design features were selected: special safety measures (such as the presence of special communication and warning systems), visibility on the ward (i.e. ward layout enables staff to see the patients - good sight lines, cameras) and the presence of a violence-proof finish (of walls, ceilings, doors and frames, locking devices and type of glass). A number of design features were also selected from the families 'privacy' (referring to the level of privacy of patients), 'comfort and control' (referring to the indoor ambient conditions and personal control of surroundings) and 'rooms for seclusion'. From the small family 'facility level', only 'presence of a nursing station' was selected. From the family 'daylight, views and nature', only 'presence of an outdoor space or garden' was selected. It seems that the families 'facility level' and 'daylight, views and nature' are less important in comparison to other families.

Then the second series of multilevel analyses were performed, which included all patient, staff and general characteristics, in addition to all 14 previously selected design features. Overall, the 14 selected design features had a significant effect on the risk of being secluded during admission $\left(\Delta \chi^{2}=45.89, \Delta\right.$ d.f. $=14$, $P<0.001)$. Design features increasing the risk of being secluded were (Table 4): 'presence of an outdoor space' $(\mathrm{OR}=9.09)$, the availability of 'special safety measures' $(\mathrm{OR}=1.60)$ and a large 'number of patients in the building' $(\mathrm{OR}=1.01)$. Design features

\begin{tabular}{|c|c|c|c|}
\hline \multirow[b]{2}{*}{ Ward characteristics, design features } & \multicolumn{3}{|c|}{ Type of ward } \\
\hline & Admission $(n=82)$ & Non-admission $(n=92)$ & Forensic $(n=25)$ \\
\hline \multicolumn{4}{|l|}{ Privacy } \\
\hline Number of patients on the ward, mean (s.d.) & $12.9(4.8)$ & $12.4(5.7)$ & $10.0(3.06)$ \\
\hline Number of patients in the building (including other wards), mean (s.d.) & $41.6(22.7)$ & $52.5(28.1)$ & $37.4(15.8)$ \\
\hline Size (total $\mathrm{m}^{2}$ ), mean (s.d.) & $462.6(187.6)$ & $474.5(244.5)$ & $398.9(160.9)$ \\
\hline Private space per patient $\left(m^{2}\right)$, mean (s.d.) & $12.7(3.1)$ & $14.2(4.2)$ & $14.7(1.0)$ \\
\hline Common space per patient $\left(m^{2}\right)$, mean (s.d.) & $10.1(3.2)$ & $10.4(3.4)$ & $9.8(3.0)$ \\
\hline Beds in single rooms, proportion of total beds, \% (s.d.) & $92.3(16.3)$ & $93.0(15.0)$ & $100(0.0)$ \\
\hline Toilets for single use, proportion of total toilets, \% (s.d.) & $41.4(41.8)$ & $29.1(39.5)$ & $76.9(25.5)$ \\
\hline Bedroom doors can be locked by patients, $n(\%)$ & $57(69.5)$ & $51(55.4)$ & $6(24.0)$ \\
\hline \multicolumn{4}{|l|}{ Daylight, views and nature } \\
\hline Presence of outdoor space, $n(\%)$ & $78(95.1)$ & $89(96.7)$ & $25(100.0)$ \\
\hline \multicolumn{4}{|l|}{ Comfort and control } \\
\hline Personal furniture, $n(\%)$ & $18(22.0)$ & $47(51.1)$ & $1(4.0)$ \\
\hline Patients can open the window, $n(\%)$ & 79 (96.3) & $88(95.7)$ & $11(44.0)$ \\
\hline Patients can control the room temperature, $n(\%)$ & 79 (96.3) & $84(91.3)$ & $25(100.0)$ \\
\hline \multicolumn{4}{|l|}{ Facility level } \\
\hline Presence of a nursing station, $n(\%)$ & $63(77)$ & $55(60)$ & $21(84)$ \\
\hline Number of rooms for common use, mean (s.d.) & $3.0(0.8)$ & $2.7(0.8)$ & $3.2(0.6)$ \\
\hline \multicolumn{4}{|l|}{ Safety } \\
\hline Door position monitoring, $n(\%)$ & $4(5)$ & $8(9)$ & $11(44)$ \\
\hline Violence-proof finish, $n$ (\%) & $12(15)$ & $8(9)$ & $6(24)$ \\
\hline Observation by cameras, $n(\%)$ & $19(23)$ & $24(26)$ & $12(48)$ \\
\hline Patients have electronic pass/key, flexible access, $n$ (\%) & $9(11)$ & $11(12)$ & $3(12)$ \\
\hline \multicolumn{4}{|l|}{ Rooms for seclusion } \\
\hline Total number of seclusion rooms, mean (s.d.) & $1.6(1.0)$ & $1.1(1.2)$ & $1.5(0.5)$ \\
\hline $\begin{array}{l}\text { Number of locked (bed)rooms or otherwise designated areas that } \\
\text { can be locked, mean (s.d.) }\end{array}$ & $3.5(4.2)$ & $4.7(6.6)$ & $9.1(5.0)$ \\
\hline
\end{tabular}




\begin{tabular}{|c|c|c|c|}
\hline \multirow[b]{2}{*}{ General ward characteristics } & \multicolumn{3}{|c|}{ Type of ward } \\
\hline & Admission $(n=82)$ & Non-admission $(n=92)$ & Forensic $(n=25)$ \\
\hline Non-rural area, $n$ (\%) & $74(90.2)$ & $81(88.0)$ & $24(96.0)$ \\
\hline \multicolumn{4}{|l|}{ Year of construction, $n(\%)$} \\
\hline Up to 1983 & $16(19.5)$ & $20(21.7)$ & $2(8.0)$ \\
\hline 1984-1993 & $23(28.0)$ & $15(16.3)$ & $14(56.0)$ \\
\hline 1994-2003 & $25(30.5)$ & $33(35.9)$ & $0(0.0)$ \\
\hline From 2004 & $18(22.0)$ & $24(26.1)$ & $9(36.0)$ \\
\hline \multicolumn{4}{|l|}{ Staffing, mean (s.d.) } \\
\hline Equivalent full-time staffing per bed & $1.4(0.7)$ & $1.5(0.9)$ & $1.4(0.5)$ \\
\hline \multicolumn{4}{|l|}{ Admissions, mean (s.d.) } \\
\hline Number of admissions in 2009-2010 & $187.8(163.6)$ & $90.0(91.5)$ & $41.1(33.8)$ \\
\hline Length of stay, days & $78.3(62.9)$ & $120.8(73.9)$ & $124.6(69.8)$ \\
\hline \multicolumn{4}{|l|}{ Coercive measures, mean (s.d.) } \\
\hline Seclusion incidents per 1000 admissions & $187.4(216.8)$ & $162.7(401.5)$ & $243.7(297.6)$ \\
\hline Seclusion hours & $116.6(270.6)$ & $140.7(350.7)$ & $239.7(534.6)$ \\
\hline Seclusion hours (proportion) & $0.9(5.5)$ & $0.7(3.8)$ & $1.2(3.4)$ \\
\hline Coercive measures per 1000 admissions & $545.1(1470.4)$ & $544.4(962.9)$ & $686.1(613.2)$ \\
\hline
\end{tabular}

\begin{tabular}{|c|c|c|}
\hline Design features & OR $(95 \% \mathrm{Cl})$ & $P$ \\
\hline Total private space per patient $\left(\mathrm{m}^{2}\right)$ & $0.88(0.82-0.95)$ & $<0.001$ \\
\hline Observation bedrooms & $0.78(0.50-1.23)$ & 0.284 \\
\hline Number of patients in the building & $1.01(1.00-1.02)$ & 0.034 \\
\hline Presence of outdoor space or garden (yes v. no) & $9.09(2.31-35.78)$ & 0.002 \\
\hline Comfort & $0.77(0.61-0.97)$ & 0.026 \\
\hline Personal furniture (yes $v$. no) & $0.81(0.51-1.28)$ & 0.370 \\
\hline Type of ventilation & $0.84(0.49-1.42)$ & 0.509 \\
\hline Presence of a nursing station (yes v. no) & $1.03(0.63-1.68)$ & 0.915 \\
\hline Special safety measures & $1.60(1.09-2.33)$ & 0.016 \\
\hline Visibility on the ward & $0.69(0.49-0.97)$ & 0.032 \\
\hline Violence-proof finish & $1.30(0.59-2.87)$ & 0.512 \\
\hline Number of seclusion rooms (ward) & $1.12(0.89-1.41)$ & 0.338 \\
\hline Number of seclusion rooms (building) & $1.24(0.90-1.70)$ & 0.183 \\
\hline Number of bedrooms that can be locked & $1.25(0.58-2.72)$ & 0.568 \\
\hline
\end{tabular}

decreasing the risk of being secluded were: more 'total private space per patient' $(\mathrm{OR}=0.88)$, a higher 'level of comfort' $(\mathrm{OR}=0.77)$ and greater 'visibility on the ward' $(\mathrm{OR}=0.69)$.

\section{Multilevel analysis: design features and other outcome measures}

The analyses with the two other outcome measures for seclusion showed no significant overall effect, neither for the number of seclusions $\left(\Delta \chi^{2}=10.66, \Delta\right.$ d.f. $\left.=6, P=0.099\right)$, nor for the duration of seclusion $\left(\Delta \chi^{2}=4.77, \Delta\right.$ d.f. $\left.=2, P=0.092\right)$, while controlling for patient, staff and general ward characteristics. The impact of most of the selected design features, at the time the first series of multilevel analyses per family were performed, became non-significant once all other variables were entered into the model.

\section{Discussion}

\section{Main findings}

This study is based on a large number of wards, includes a large number of design features and covers all seclusion and restraint incidents recorded on these wards during a 1 -year period. The findings suggest that the physical environment of the ward had a significant effect on the risk of being secluded during admission, even after patient, staff and general ward characteristics were taken into account. Although not described in detail here, similar effects were found when we looked at all coercive measures used during admission (total incidents per admission), as well as the risk of being secluded in a room other than a seclusion room, such as a time-out room, an isolation room or a stripped bedroom. The number of seclusions and the duration of separation showed no significant effects. This may be the result of the very skewed distributions of both variables.

Within the family of 'safety', all three design features showed significant effect on seclusion and were therefore included in the final multilevel analysis. From the families 'privacy', 'comfort and control' and 'rooms for seclusion', a number of design features were selected. From the other two families, only 'presence of a nursing station' and 'presence of an outdoor space or garden' showed significant effect within the family and were selected for the final analysis.

Overall, a higher risk of being secluded was detected for 'the presence of an outdoor space', the availability of 'special safety measures on the ward' and a large 'number of patients in the 
building'. A lower risk of being secluded was found for more 'total private space per patient', a higher 'level of comfort' and greater 'visibility on the ward'. The finding of an increase in risk of seclusion with the presence of an outdoor space or garden is not consistent with the literature. Several studies have demonstrated that exposure to natural elements, such as a garden, is associated with increased positive affect, comfort, psychological well-being, recovery from fatigue and stress and fewer behavioural problems. Views of nature, landscape paintings, as well as indoor plants, have similar restorative effects among patients. ${ }^{28,29}$ However, our information was limited to two items: the presence of an outdoor space (yes or no) and the height of the fences. Other relevant information, such as the quality or attractiveness of the outdoor space or garden and whether or not patients actually had (free and/or unsupervised) access to the outdoor space, was not documented. This might have been useful in explaining the increased risk found in this study. Only 3.5\% (95\% CI 2.3-35.9) of the wards in our sample did not have an outdoor space. Therefore the effect of outdoor space might be biased.

'Special safety measures' such as the presence of locking devices on doors with delayed alarm and opening, door position monitoring and the type of communication system for staffpatient interaction that was used, also increased the risk of being secluded. This effect may well be explained by the impersonal, restrictive and institutionalised atmosphere that often occurs when special safety measures are being taken, especially on wards with a strong emphasis on safety. This might lead to responses such as anxiety, crowding, conflict and aggression that can culminate in seclusion and restraint. Studies indicate that unwanted and even threatening behaviours are associated with institutional settings. ${ }^{30-32}$ On the other hand, visibility on the ward in our study decreased the risk of being secluded. It is often suggested that wards that rank high on visibility (i.e. cameras, wider corridors, good overview and sight lines) tend to have a more institutionalised, less pleasant atmosphere. However, visibility can also have beneficial effects for patients and staff and their (sense of) security. Our findings suggest that, compared with other safety measures, visibility is less intruding/intimidating or obtrusive for patients. Unobtrusive safety measures, that do not hinder a pleasant, more homelike atmosphere, seem to be preferable.

Factors decreasing the likelihood of seclusion were found for design features that related to the privacy and autonomy of patients, such as the total private space per patient, a small number of patients in the building and the level of comfort. Private space offers patients territorial control, feelings of ownership, identity, a sense of dignity and the ability to regulate social interaction, which all enhances the well-being of patients. It is also related to better adjusted behaviour and better functioning. ${ }^{32-34}$ Lack of comfort and personal control over the physical environment can lead to distress and helplessness. ${ }^{33}$

However, no effects were found for the total size of the ward, the facility level (type and number of common rooms, total common space) and the number of patients on the ward itself. This suggests that private space is more important than common space, when it comes to the risk of being secluded. However, other studies have demonstrated that spaces where patients can get away and be alone may buffer some of the harmful effects of crowding, increase well-being and can offer some distraction. ${ }^{35}$

\section{Limitations of the study}

A limitation of the study was that we could not include more variables that are associated with aggression and the use of coercive measures on psychiatric wards. At least three groups of variables are relevant to future research. First, the use of medication and treatment (including patient-staff communication). We only included the use of enforced intramuscular medication and could not include psychopharmacological treatments, which can mediate (disturbed) patients' behaviour as well. Second, the use of coercive measures is related to the culture and the attitudes of the staff towards coercive measures and restraint in general, work routines and the organisation. ${ }^{36}$ Variables such as staff number, mix and training may also be relevant. ${ }^{20}$ Third, a variety of initiatives can be used to reduce coercive and restraint, such as first-admission engagement, aggression training and risk assessment. Our information was limited in that we only asked whether measurements were taken (yes/no); we did not ask what kind of measurements were used. It may be, that these other variables, and their potential effects, are evenly distributed over the wards, which may be expected in the case of a large sample size like in our study.

Finally, we used a rather extreme and specific outcome measure to explore the impact of the physical environment on patients. Adding other outcome measures such as self-reported well-being, satisfaction, quality of life or other patient outcomes might have enabled us to discover a broader range of design features that may have a positive effect on patients.

\section{Implications}

Our study supports the idea that the physical environment of the ward has an effect on the use of seclusion and restraint. Adjusted effects were found for several design features, related to the privacy and autonomy of patients, the level of safety and the atmosphere of the ward. This emphasises the importance of reassurance, identity, privacy and normality, when designing wards for intensive psychiatric care. ${ }^{37}$ It seems that obtrusive safety measures, at the expense of a pleasant homelike atmosphere, should be avoided. Our findings may contribute to a reduction of seclusion and restraint, and identify important elements that should be taken into consideration when designing psychiatric hospitals. The latter can be done by translating the findings into design recommendations, primarily using the findings from the multilevel analyses. The univariate relationships identified in this study, where we only controlled for patients' length of stay, may be attributed to hospital design and may add value for patients. Finally, our findings highlight that, along with other important interventions, ${ }^{38}$ there should be a greater focus within mental healthcare on the role and function of the physical environment of the ward for the well-being of patients and reducing the need for seclusion and restraint.

P. S. van der Schaaf, MSC, E. Dusseldorp, PhD, F. M. Keuning, TNO Behavioural
and Societal Sciences, Soesterberg, The Netherlands; W. A. Janssen, PhD, E. O. Noorthoorn, PhD, Kenniscentrum GGNet, Warnsveld, The Netherlands

Correspondence: P. S. van der Schaaf, TNO, Dutch Centre for Health Assets/DuCHA Kampweg 5, 3769 DE Soesterberg, The Netherlands. Email: psvdschaaf@hotmail.com

First received 26 Jul 2012, final revision 20 Nov 2012, accepted 10 Dec 2012

\section{Funding}

The study was funded by the Dutch Ministry of Health, Welfare and Sport.

\section{References}

1 Mason T, Alty A. Seclusion and Mental Health: A Break with the Past. Chapman \& Hall, 1994

2 Currier GW. The controversy over 'chemical restraint' in acute care psychiatry. J Psychiatr Prac 2003; 9: 59-70. 


\section{Appendix}

\section{Families of design features and non-linear principal components analysis (CATPCA) components}

\section{Families}

Privacy

Daylight, views and nature

Comfort and control

Facility level

Safety

Rooms for seclusion
Design features of the ward and CATPCA-components $(\alpha)$

Individual space and privacy

Total private space per patient $\left(\mathrm{m}^{2}\right)$

Bedroom doors can be locked by patients (\%)

Number of patients on the ward AND number of patients in the building (including other wards)

Observation bedrooms $(\alpha=0.61)$

Contact and accessibility of outdoor space

Type of view in living room

Window size in bedrooms (daylight admission)

Presence of outdoor space or garden (yes $v$. no)

View outside $(\alpha=0.70)$

Personalisation opportunities and ability to control comfort levels

Personal furniture (yes $v$. no)

Type of ventilation

Patients can open the window (yes $v$. no)

Patients can control the temperature (yes $v$. no)

Comfort $(\alpha=0.76)$

Type and number of facilities for leisure or treatment

Presence of a nursing station (yes $v$. no)

Facility level $(\alpha=0.59)$

Special safety measures on the ward

Visibility on the ward $(\alpha=0.65)$

Violence-proof finish $(\alpha=0.68)$

Special safety measures $(\alpha=0.71)$

Rooms or spaces for seclusion, including alternatives

Number of seclusion rooms on the ward AND number of seclusion rooms in the building

Number of bedrooms that can be locked

Presence of time-out, isolation or otherwise designated areas that can be locked (yes $v$. no)

Presence of spatial alternatives for seclusion (yes $v$. no)
3 Sailas E, Fenton M. Seclusion and Restraint for People with Serious Mental Illnesses (Cochrane Review). The Cochrane Library, 2003.

4 Olofsson B, Norberg A. Experiences of coercion in psychiatric care as narrated by patients, nurses and physicians. J Adv Nurs 2001; 33: 89-97.

5 Inspectie voor de Gezondheidszorg. Terugdringen Separeren Stagneert, Normen Vereist Rondom Insluiting Psychiatrische Patiënten [Reduction of Seclusion in Stagnating, Standards are Required for the Seclusion of Psychiatric Patients]. Inspectie voor de Gezondheidszorg, 2011.

6 Nijman HLI, Allertz W, Merckelbach HLGJ, à Campo JLMG, Ravelli DP. Aggressive behaviour on an acute psychiatric admissions ward. Eur J Psychiat 1997; 11: 106-14

7 Bowers L, Allan T, Simpson A, Jones J, Van Der Merwe M, Jeffery D. Identifying key factors associated with aggression on acute inpatient psychiatric wards. Issues Ment Health Nurs 2009; 30: 260-71.

8 Bower FL, McCullough CS, Timmons ME. A synthesis of what we know about the use of physical restraint and seclusion with patients in psychiatric and acute care settings. Online J Knowl Synth Nurs 2003; 10: 1.

9 Wynn R. Medicate, restrain or seclude? Strategies for dealing with violent and threatening behaviour in a Norwegian university psychiatric hospital. Scand J Caring Sci 2002; 16: 287-91.

10 Taylor TL, Killaspy H, Wright C, Turton P, White S, Kallert TW, et al A systematic review of the international published literature relating to quality of institutional care for people with longer term mental health problems. BMC Psychiatry 2009; 9: 55.

11 Vaaler $\mathrm{AE}$, Morken $\mathrm{G}$, Linaker OM. Effects of different interior decorations in the seclusion area of a psychiatric acute ward. Nord J Psychiatry 2005; 59: 19-24.

12 Wilson MR, Soth N, Robak R. Managing disturbed behavior by architectural changes; making space fit the program. Milieu Ther 1983; 2: 15-24.

13 Dijkstra K, Pieterse ME, Pruyn A. Physical environmental stimuli that turn healthcare facilities into healing environments through psychologically mediated effects, systematic review. J Adv Nurs 2006; 56: 166-81.

14 Gross R, Sasson $Y$, Zarhy M, Zohar J. Healing environment in psychiatric hospital design. Gen Hosp Psychiatry 1998; 20: 108-14.
15 Ulrich R, Quan X, Zimring C, Joseph A, Choudhary R. The Role of the Physical Environment in the Hospital of the 21st Century: A Once-in-a-Lifetime Opportunity. Center for Health Systems and Design, Texas A\&M University, 2004.

16 Steinert T, Lepping P, Bernhardsgrütter R, Conca A, Hatling T, Janssen W, et al. Incidence of seclusion and restraint in psychiatric hospitals: a literature review and survey of international trends. Soc Psychiatry Psychiatr Epidemiol 2009; 46: 889-97.

17 Soorgaard KW. Patients' perceptions of coercion in acute psychiatric wards: an intervention study. Nord J Psychiatry 2004; 58: 4-8.

18 Moran A, Cocoman A, Scott P, Matthews A, Staniuliene V, Valimaki M. Restraint and seclusion: a distressing treatment option? J Psychiatr Ment Health Nurs 2009; 16: 599-605.

19 Janssen WA, Sande van de R, Noorthoorn EO, Nijman HLI, Bowers L, Mulder $\mathrm{CL}$, et al. Methodological issues in monitoring the use of coercive measures. Int J Law Psychiatry 2011; 34: 429-38.

20 Janssen WA, Noorthoorn EO, Nijman HLI, Bowers L, Hoogendoorn AW, Smit A, et al. Differences in seclusion rates between admission wards: does patient compilation explain? Psychiatr Q 2012; May 12 (Epub ahead of print).

21 van der Aalst H, Keuning F, Maas-Calon M, Mimpen L. Gesloten Huisvesting in de Geestelijke Gezondheidszorg [Quality and Safety of Buildings for Psychiatric Care]. TNO, 2010.

22 Janssen WA, Noorthoorn EO, de Vries WJ, Hutschemeakers GJ, Lendemeijer $\mathrm{HH}$, Widdershoven GA. The use of seclusion in the Netherlands compared to countries in and outside Europe. Int J Law Psychiatry 2008; 31: 463-70.

23 World Health Organization. The ICD-10 Classification of Mental and Behavioural Disorders: Clinical Descriptions and Diagnostic Guidelines. WHO, 1992.

24 Startup $M$, Jackson $M$, Bendix S. The concurrent validity of the Global Assessment of Functioning (GAF). Br J Clin Psychol 2002; 41: 417-22.

25 Ulrich RS, Zimring C, Zhu X, DuBose J, Seo H, Choi Y, et al. A review of the research literature on evidence-based healthcare design. HERD 2008; 1 : 102-65.

26 Gifford R. Environmental Psychology. Principles and Practice (4th edn). Optimal Books, 2007. 
27 Linting M, Meulman J, Groenen, P, van der Kooij A. Nonlinear principal components analysis: introduction and application. Psychol Methods 2007: 12: $336-58$.

28 Ulrich RS, Simon RF, Losito BD, Fiorito E, Miles MA, Zelson M. Stress recovery during exposure to natural and urban environments. J Environ Psychol 1991; 11: $201-30$

29 Dijkstra K, Pieterse ME, Pruyn A. Stress-reducing effects of indoor plants in built healthcare environment. The mediating role of perceived attractiveness Prev Med 2008; 47: 279-83.

30 Zeisel J, Silverstein NM, Hyde J, Levkoff S, Powell Lawton M, Holmes W. Environmental correlates to behavioral health outcomes in Alzheimer's special care units. Gerontologist 2003; 43: 697-711.

31 Bowie $\mathrm{P}$, Mountain $\mathrm{G}$, The relationship between patient behaviour and the environmental quality for the dementing. Int I Geriatr Psychiatry 1997: 12: 718-23.

32 Middelboe T, Schjødt T, Byrsting $\mathrm{K}$, Gjerris A. Ward atmosphere in acute psychiatric in-patient care: patients' perceptions, ideals and satisfaction. Acta Psychiatr Scand 2001; 103: 212-9.
33 Evans GW. The build Environment and Mental Health. J Urban Health 2003; 80: $536-55$.

$34 \mathrm{Karlin} \mathrm{BE}$, Zeiss RA. Environmental and therapeutic issues in psychiatric hospital design: toward best practices. Psychiatr Serv 2006; 57: 1376-8.

35 Evans GW, Mitchell McCoy J. When buildings don't work: the role of architecture in human health. J Environ Psychol 1998; 18: 85-94.

36 Bowers $L$, van der Werf $B$, Vokkolainen A, Muir-Cochrane $E$, Allan $T$, Alexander J. International variation in attitudes to coercive measures for disturbed psychiatric inpatients. Int J Nurs Stud 2007; 44: 357-64.

37 Douglas $\mathrm{CH}$, Douglas MR. Patient-centred improvements in healthcare built environments: perspectives and design indicators. Health Expect 2005; 8 264-76.

38 Gaskin CJ, Elsom SJ, Happell B. Interventions for reducing the use of seclusion in psychiatric facilities. Review of the literature. Br J Psychiatry 2007; 191: 298-303.

\section{poem}

\section{Ice}

\section{John Exell}

It is winter.

In my breast it is winter too.

Icicles live where once beat my heart.

I do not long for spring,

Winter suits me.

Its coldness is bracing, awakening

It numbs the pain.

Love caused this pain.

I now stand aloof from love,

What need have I for it?

The ice forms patterns on my window.

Beautiful geometric ordered patterns,

A true mathematical beauty.

What need have I for the false beauty of her eyes, her lips?

I lay on my bed to sleep

No more will I lose myself in dreams.

I sleep the sleep of death,

Stillness, ice, ice, death.

Ice is stillness, solid, unyielding

Frozen water, frozen tears.

John Exell's poetry was published by Survivors' Poetry in 2006 as part of Survivors' Poetry Mentoring Series. He was mentored by Peter Campbell.

Chosen by Femi Oyebode. 